\section{Partnering to address rural health workforce challenges in Western NSW}

Rural health workforce challenges

Robyn Ramsden

School of Health and Social Development, Deakin University, Melbourne, Australia Richard Colbran

NSW Rural Doctors Network, Newcastle, Australia

Tricia Linehan

Health Intelligence Unit, Orange, Australia

Michael Edwards

NSW Rural Doctors Network, Newcastle, Australia

Hilal Varinli

Health Intelligence Unit, Orange, Australia

Carolyn Ripper and Angela Kerr

NSW Rural Doctors Network, Newcastle, Australia

Andrew Harvey

Western NSW PHN, Dubbo, Australia

Phil Naden

Bila Munji Aboriginal Corporation Health Service, Dubbo, Australia

Scott McLachlan

Western NSW Local Health District, Dubbo, Australia, and

Stephen Rodwell

Far West Local Health District, Broken Hill, Australia

\section{Abstract}

Purpose - While one-third of Australians live outside major cities, there are ongoing challenges in providing accessible, sustainable, and appropriate primary health care services in rural and remote communities. The purpose of this paper is to explore a partnership approach to understanding and addressing complex primary health workforce issues in the western region of New South Wales (NSW), Australia.

Design/methodology/approach - The authors describe how a collaboration of five organisations worked together to engage a broader group of stakeholders and secure commitment and resources for a regional approach to address workforce challenges in Western NSW. A literature review and formal interviews with stakeholders gathered knowledge, identified issues and informed the overarching approach, including the development of the Western NSW Partnership Model and Primary Health Workforce Planning Framework. A stakeholder forum tested the proposed approach and gained endorsement for a collaborative priority action plan.

Findings - The Western NSW Partnership Model successfully engaged regional stakeholders and guided the development of a collaborative approach to building a sustainable primary health workforce for the future.

(C) Robyn Ramsden, Richard Colbran, Tricia Linehan, Michael Edwards, Hilal Varinli, Carolyn Ripper, Angela Kerr, Andrew Harvey, Phil Naden, Scott McLachlan and Stephen Rodwell. Published by Emerald Publishing Limited. This article is published under the Creative Commons Attribution (CC BY 4.0) licence. Anyone may reproduce, distribute, translate and create derivative works of this article (for both commercial \& non-commercial purposes), subject to full attribution to the original publication and authors. The full terms of this licence may be seen at: http://creativecommons.org/licences/by/4.0/legalcode 
JICA

28,2

146

Originality/value - Given the scarcity of literature about effective partnerships approaches to address rural health workforce challenges, this paper contributes to an understanding of how to build sustainable partnerships to positively impact on the rural health workforce. This approach is replicable and potentially valuable elsewhere in NSW, other parts of Australia and internationally.

Keywords Partnership working, Collaboration, Partnership model, Rural and remote health workforce, Rural and remote primary health care, Rural workforce challenges

Paper type General review

\section{Introduction}

The Australian health care system "[...] has come under intense pressure due to changes in healthcare needs, such as the increase in demand and healthcare costs, inequities, complex health conditions and a push to improve health outcomes" (Dixit and Sambasivan, 2018, p. 1). The challenges in providing effective, timely, coordinated health care now and into the future have led to a renewed focus on the importance of primary health care and its role in delivering better health outcomes at lower cost (AIHW, 2014).

In Australia, primary health care is typically the first health service accessed by patients with a health concern (AIHW, 2016). It includes health promotion, prevention, early intervention, treatment of acute conditions and management of chronic conditions (DoH, 2015). Various services are provided by the primary health care sector and are delivered in numerous settings - such as General Practices, community health centres, Aboriginal Community Controlled Health Services (ACCHSs), allied health practices, in-home care and more recently telecommunications technologies such as health advice telephone services, video consultations and remote monitoring of health metrics through electronic devices (AIHW, 2016).

Evidence suggests that a strong primary health care orientation within the health service system exerts a positive effect on both population health outcomes and overall health system costs (AIHW, 2018; OECD, 2017). Effective primary health care can also improve outcomes at a lower cost than hospital and secondary care, and help to avoid unnecessary hospitalisations (OECD, 2017). However, Australia's primary health care system faces several ongoing challenges. These include inequalities in access to effective and coordinated care, as well as increasing demand due to an ageing population and rising levels of chronic conditions and risk factors (AIHW, 2018). Further challenges to Australia's primary health care system relate to the need to optimise health access for locationally disadvantaged populations in particular in rural and remote regions (Wakerman and Humphreys, 2011). In 2018, approximately 32.7 per cent of Australians lived outside greater capital city areas and 28.2 per cent lived outside major cities (ABS, 2018).

\section{Primary health care challenges in remote and rural areas}

Australians living in rural and remote areas generally experience poorer health and welfare outcomes than people living in metropolitan areas. They have higher rates of chronic disease and mortality, poorer access to health services, are more likely to engage in behaviours associated with poorer health and are over-represented in the child protection and youth justice sectors (AIHW, 2018). The problem of how to provide accessible, sustainable, appropriate primary health care services is most acute in small rural and remote communities, where the increased costs and difficulties of workforce recruitment and retention are compounded by the lack of economies of scale associated with servicing small populations dispersed over vast distances (Humphreys et al., 2008).

\section{Primary health care in Western NSW}

The Western New South Wales (NSW) region covers a total area of 433,379 square kilometres. The total population of the region is estimated to be more than 313,600 people (Australian Government, 2019). More than a third of the Western NSW region's local 
government areas are classified as remote or very remote under the Modified Monash Model [1] (see Figure 1) (DoH, 2018).

Primary health care in Western NSW is supported by both government and nongovernment organisations funded by both the NSW and Australian Governments. The two NSW Government health organisations in this region, Western NSW Local Health District (WNSWLHD) and Far West Local Health District (FWLHD), provide a range of services for their respective populations including both acute and primary care. The ACCHSs and Aboriginal Health Services deliver culturally appropriate comprehensive primary health care to their communities in Western NSW. The Western NSW Primary Health Network (WNSW PHN) is one of 31 PHNs established by the Australian Government and is geographically the largest in NSW. The PHN is not a frontline provider of health care services; instead, it seeks to align services with the health needs of the region and funds health care providers to deliver a range of primary health care services that are appropriate and relevant to the needs of the community. These organisations work closely with General Practice, other health care providers, the broader community and the designated Rural Workforce Agency for health in NSW - NSW Rural Doctors Network (RDN).

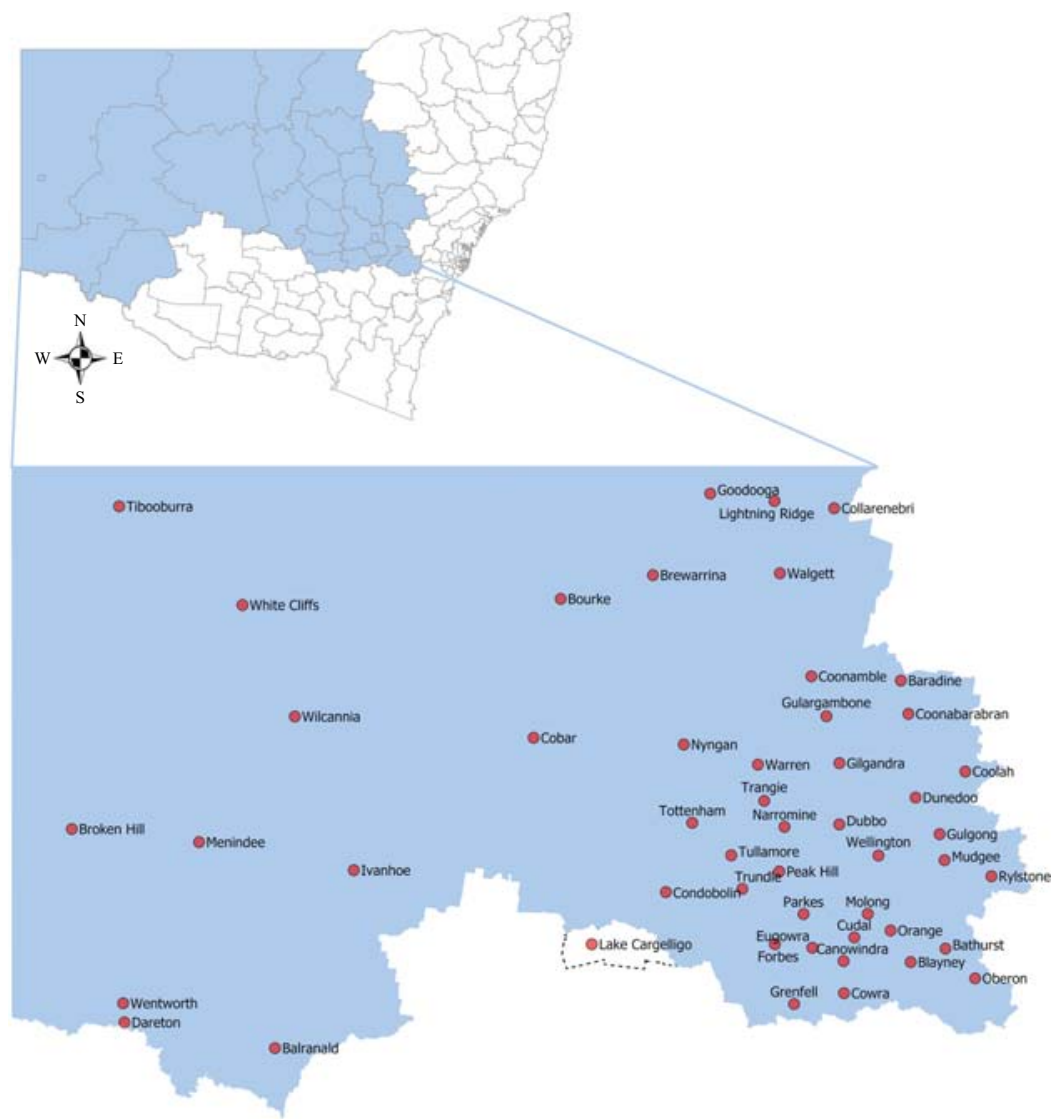

Source: NSW Rural Doctors Network (22 October 2019)
Rural health workforce challenges
Figure 1. Western NSW 
JICA

28,2

148

\section{Primary health care challenges in Western NSW}

The geographical isolation, social and health inequities faced by many in Western NSW contribute to the challenges in accessing health services. The region has some particularly vulnerable populations that generally have a lower socio-economic status, shorter life expectancy and poorer health than other people living in NSW. In Western NSW, 12 per cent of the population identifies as Aboriginal, compared to only 3 per cent for all NSW (PHIDU, Aboriginal population by LGA, 2019). Of that 12 per cent, 11 per cent resides in the FWLHD and 89 per cent resides in the WNSWLHD (Figure 1). Compared to the NSW population, Western NSW has more people under 20 and 65 years or older (Australian Government Primary Health Network Western NSW, 2019). The Western NSW region also has higher health risk factors compared to the rest of NSW. In Western NSW, 22.9 per cent of people over 16 years smoke, compared with 15 per cent for NSW; 26.5 per cent of people over 16 years are obese, compared with 21.0 per cent for NSW; and 37.2 per cent of people over 16 years consume alcohol at levels posing long-term risk, compared with 31.1 per cent for NSW (NSW Government, 2017). Lower levels of adults (85.9 per cent) in the PHN region report excellent, very good or good health compared to the rest of Australia (87 per cent). The rate of potentially preventable hospitalisations in 2017-2018 per 100,000 population was 2,547.5 in Western NSW compared to 2,192.0 in NSW (NSW Government, 2017).

Attracting and retaining a skilled rural primary health workforce and the inequitable distribution of supply has reached a critical level in Western NSW, exacerbating the financial strain for organisations providing a rural workforce for the region (HIU, 2017). Over the past decade, individual organisations have focused on ways to increase the health care workforce supply, recruitment and retention to address these challenges, sometimes working and partnering with another organisation.

\section{Partnership work in health care}

The need to work collaboratively to address health challenges was highlighted in the 1986 Ottawa Charter for Health Promotion (WHO, 1986). Since then "public sector reform around the world has embraced the application of health interventions that hinge on cross sectoral and inter-organisational collaboration" (Kendall et al., 2012, p. E1). Collaborative activities are widely promoted as a solution to problems of fragmentation and poor coordination in health and social care (Glendinning, 2002; Strasser et al., 2016).

A partnership is an agreement to do something together by combining the individual perspectives, resources and skills of the partners to achieve a common goal (OECD LEED, 2006). This brings results that could not be achieved by a single partner operating alone, reducing duplication of effort. Area-based partnerships provide a mechanism for local organisations, in particular, to work together and adapt their policies to better reflect the needs of people and the economy at the local level (OECD LEED, 2006). In rural and remote areas, partnerships across health care sectors and between health care providers will help address the economic and social determinants of health that are essential to meeting the needs of these communities (Australian Government, 2016).

\section{Elements of effective partnerships}

Effective partnerships have key elements which help to create an environment that has the capacity to manage a partnership relationship over the time it takes to produce results (Keleher, 2015). The literature on partnerships, including individual case studies, increases our understanding of the contextual and specific elements of success and the common pitfalls in building and sustaining partnerships. However, while principles for effective partnerships are generally applicable (Wildridge et al., 2004), they also need to be adapted to the reality of the contexts and the needs of the partners and the local issues to determine the most suitable structure and processes for operating effectively (Mitchell and Shortell, 2000). 
Glasby et al. (2011) summarised some of the key approaches, processes and concepts that help and hinder partnership, including a shared vision, consideration of the depth and breadth of relationship required, and a focus on outcomes. Woulfe et al. (2010) reviewed the research and evaluation literature featuring multisector partnership initiatives to identify organisation and contextual factors that appeared to be associated with effective multisector partnerships. These characteristics included collaborative planning, an agreed common agenda and the pursuit of common goals, organisational capacity, partnership competencies, leadership commitment and sound communication practices to keep people engaged. Because the improvement of health care is a team effort, the issue of trust, reciprocity and respect comes to the foreground (Hardy et al., 2000). Most researchers classify trust as one of the key elements required for the development of collaborative practice (D'Amour et al., 2008; Dowling et al., 2004; Petch et al., 2013). Building trust requires time, effort, patience and previous positive experiences (Henneman et al., 1995).

Relationships appear to be central to the effective working of partnerships. A UK study of partnership working between health and the voluntary and community sector in 12 sites by Lester et al. (2008) determined the key ingredient in creating successful partnerships appeared to be reliant on an initial capacity to seek out relevant potential partners. Barriers to working more closely included differences in the time required to make and maintain relationships, and in organisational culture. A study by Pearson and Watson (2018) that drew on international lessons in integrating health and social care and empirical data collated through focus groups and interviews with health professionals also found that where integration was working, it was through individuals and their relationships with others.

Studies by Borrill and West (2002) and Woulfe et al. (2010) also highlighted the importance of effective leadership to inspire commitment and action, help the partnership to work towards inclusion, and works to sustain the vision and participation of the partnership's members. Continuing, visible and joint commitment from individuals in positions of leadership and influence was also found to be important (Hardy et al., 2000; Powell and Exworthy, 2002). While there are few case studies conducted in a rural setting, a study of two small Tasmanian rural communities and the Highlands and Islands of Scotland by Farmer and Kilpatrick (2009) examined the process of developing and sustaining partnerships between health services and their communities. They also found that leadership practices were essential in partnership development, and in particular in building the capacity in individuals and organisations to effectively partner.

While working in partnership creates opportunities for co-operation and service improvement, it also raises the potential for significant clashes of professional interests and organisational culture (Holtom, 2001). To bring together all relevant organisations is not an easy task as the interests of partners, and therefore their approach to certain problems, can be rather different and require skill and sound practice to facilitate good outcomes (OECD LEED, 2006). The costs or skills involved in negotiating, developing and maintaining thriving working relationships and translating these into successful outcomes are rarely recognised in the literature (Markwell, 2003). In a qualitative study of public health decision makers in the UK, Taylor-Robinson et al. (2012) also found that despite much support for joint working, many barriers exist. These included cultural issues such as a lack of shared values and language, commissioning and governance frameworks, resource constraints and differences in the use of evidence across sectors.

Dowling et al. (2004) and Willis et al. (2016) call for a strengthening of the evidence on multisectoral partnerships. If addressing gaps in rural health is to be more concerned with improving service delivery and user outcomes than with administrative structures and decision making, partnerships must also meet increased demands for accountability from multiple sources (Dowling et al., 2004). Partnerships and collaboration need to be deliberate, with planned actions based on a logic model and theory of change (Herranz, 2010;
Rural health workforce challenges 
JICA

28,2

Hayes et al., 2012), implement a shared measurement system and create opportunities for knowledge exchange (Willis et al., 2016).

The development of the Western NSW primary health workforce partnership While the challenges to partnership working are substantial, the benefits of collaboration can also be considerable (Dhillon, 2005). Strasser et al. (2016) observed that the sustainability of health care services in rural areas requires a multifaceted and multisectoral approach. In Western NSW, it was also recognised that to address the identified key health workforce challenges more effectively, a partnership approach was essential. The Western NSW Primary Health Workforce Partnership involved a collaboration of five organisations (see Table I) and identified an approach to engage a broader range of stakeholder organisations and regional and local committees in taking a long-term approach to addressing the key workforce challenges in the region.

\section{The Western NSW Primary Health Workforce Partnership Model}

The goal of this partnership was to ensure that primary health care workforce capability was aligned to the changing needs of the rural communities across the WNSW region, and that gaps in workforce availability were minimised through the development and implementation of a workforce partnership model.

Key organisations responsible for the delivery of health care across Western NSW considered a draft proposal outlining 11 components for achieving the goals of the project in partnership. The proposal aimed to promote working collaboratively rather than in competition and using the available resources more effectively to maximise the opportunities for successful recruitment and retention for the region. These components were implemented, sometimes concurrently, over 12 months. They form the Western NSW Workforce Partnership Model (see Figure 2).

\section{Step 1: Secure commitment for a collaborative approach (approximately one month)}

Recognition of the mounting workforce challenges in the region, the desire for a more effective use of available resources and a coordinated approach to action led to initial discussions between the WNSW PHN and RDN - two agencies with mutual interest in sustained primary

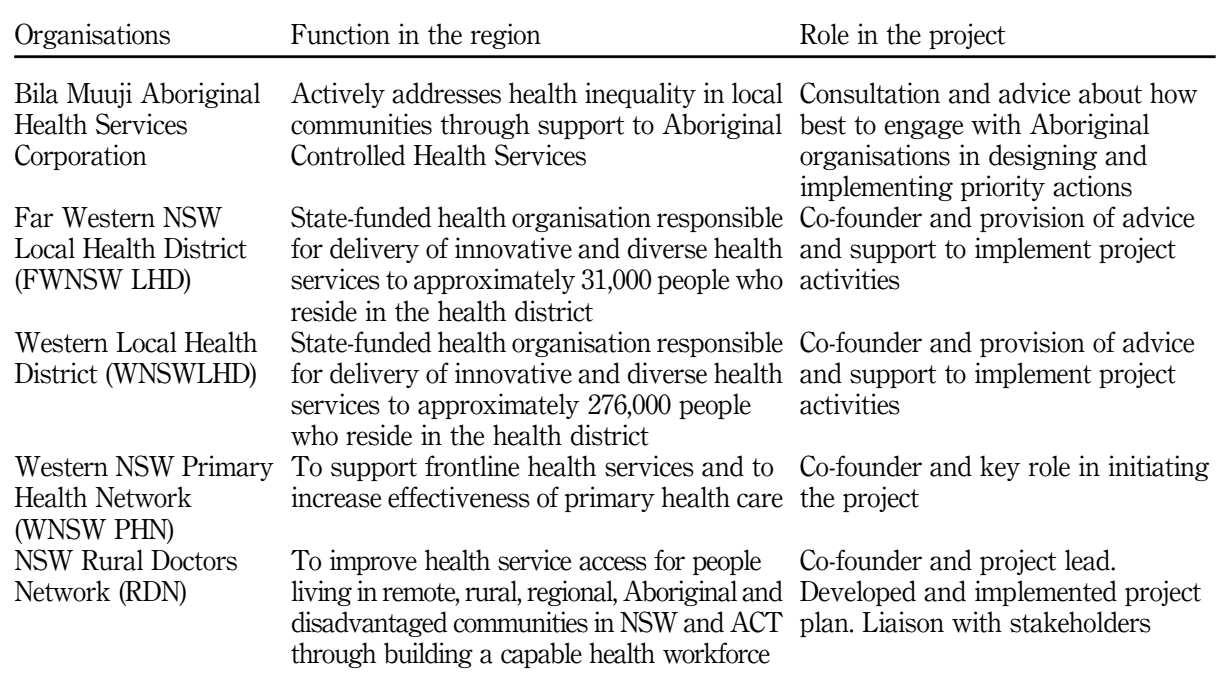

Table I.

Key partner organisations
Actively addresses health inequality in local Consultation and advice about how communities through support to Aboriginal best to engage with Aboriginal implementing priority actions State-funded health organisation responsible Co-founder and provision of advice services to approximately 31,000 people who activities reside in the health district

for delivery of innovative and diverse health and support to implement project services to approximately 276,000 people activities

To support frontline health services and to Co-founder and key role in initiating To improve health service access for people Co-founder and project lead. ving in remote, rural, regional, Aboriginal and Developed and implemented project through building a capable health workforce 


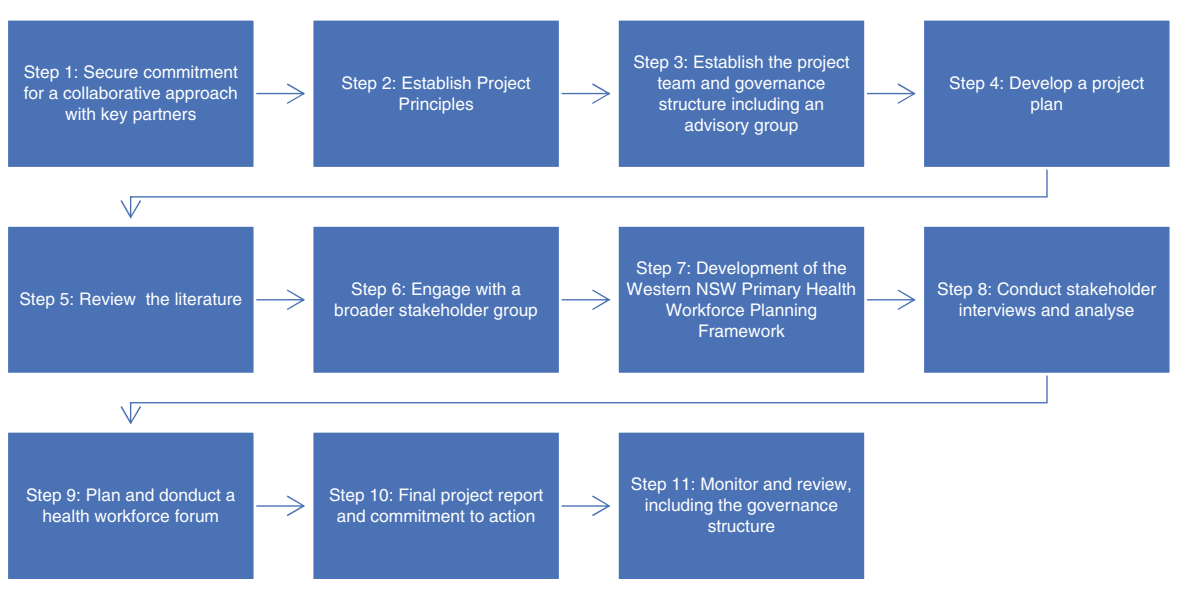

Rural health workforce challenges

151

health care workforce for the region. There was agreement that a fundamental element in local and regional planning was to identify and establish effective linkages and partnerships. It was also agreed that the region's NSW Government-funded health organisations - Western NSW and Far Western NSW Local Health Districts - should be invited to participate, and that advice would be sought from a regional network group that also included Bila Muuji Aboriginal Health Services Corporation, which represented six of the local ACCHSs in the region. These five partners brought together key regional stakeholders for an initial meeting to develop an integrated approach to primary health workforce planning. Stakeholders agreed to support the approach and the WNSW PHN and RDN made a 12-month funding commitment. The project was initiated with RDN as the lead agency.

\section{Step 2: establish the project principles (approximately one month)}

Partnership work is most effective when partners work to a set of common values and principles which accommodate the variations between organisations (Brinkerhoff, 2002). Early in the project, partners and stakeholders developed and endorsed a shared vision, service principles and expected outcomes of working in partnership. Partnership principles represented fundamental ideas about the environment and approach needed to promote an effective rural primary health workforce in Western NSW. The principles outlined a commitment to respectful, culturally safe and continuing involvement, and to the evaluation and monitoring of project activities.

\section{Step 3: form a project team and governance structure including an advisory committee (approximately one month)}

The process of developing the project plan utilised staff expertise across a range of areas within $\mathrm{RDN}$, including the recruitment and workforce development, workforce planning, health outreach, regional partnerships, future workforce and information and translation units to inform the strategy. A project Steering Committee was formed utilising key experts in rural health workforce from within WNSW and RDN to guide activities. Meetings were also conducted with representatives from each of the partner organisations to guide the project. Later, a Partnership Manager and a Reference Group were engaged to guide implementation of the process.

\section{Step 4: develop a project plan (approximately six weeks)}

A project plan identified the scope, key activities and cost aligned to the 12-month implementation timeframe. The plan also identified planning assumptions and decisions, identified potential risks and facilitated communication among key partners. 
JICA

28,2

152

Step 5: engage with a broader stakeholder group (approximately four months)

Identifying key stakeholders and carefully formulating a strategy for securing their investment in the approach was important as many of these organisations operated in a competitive environment. RDN asked the question, "How do we best build a collaborative culture within an environment of separate organisations with independent strategic aims?" It was decided to examine the corporate objectives and documents of each of the stakeholders to find common linkages.

Prioritising stakeholder engagement in waves was a further key to success. A range of factors were considered to determine the first wave, including the nature of the service provided, quality of local relationships and the degree of competition the provider operated in. The RDN CEO used this information to meet with CEOs of the identified organisations and clinical leaders to establish support for the collaborative approach. This personalised approach was a key factor in the successful engagement of stakeholders. A communication plan was developed to ensure that both formal and informal means of communication continued the engagement of stakeholders throughout the process.

\section{Step 6: review the literature (approximately two months)}

A literature review strategy which involved a search of Google scholar, key electronic databases, (including MEDLINE, PubMED, PsychINFO), and the grey literature, (including existing RDN and PHN documents) informed every other stage of the project. Efforts to define the best approach for achieving the partnership goals utilised the partnership literature to answer the questions, "What are the important steps to engage partners in addressing the critical workforce issues in the region?" and "What approaches would enable us to gather the best information and evidence to help the partnership determine some priority actions?" The project team produced a summary of the key literature findings, which also informed the development of the Western NSW Primary Health Workforce Planning Framework.

\section{Step 7: the Western NSW Primary Health Workforce Planning Framework \\ (the framework) (approximately four months)}

Working with key partners, RDN developed the Framework (see Figure A1) to guide regional health workforce policy, planning and investment throughout the next decade, recognising that a collaborative, multi-agency approach is needed to effectively tackle these health workforce issues.

The one-page conceptual Framework provides a graphic representation of the four goal areas (people, place, community/environment and performance) under which six priority action areas were identified (recruitment, retention, addressing need, strong partnerships, professional development and training and strengthening coordination). Enablers and quality improvement measures were also identified as core elements of the Framework.

Informed by the partnership literature, the Framework was integral to the project. It was used as a tool to engage stakeholders in discussion about effective strategies in the rural context. "Have we identified the key issues and areas of work?" "Is this Framework useful to conceptualise a way forward?" "Will you engage in this collaborative work?" In doing so, it made explicit the evidence-informed assumptions about how to meet the health challenges proactively and ensure that actions are sustainable and linked to an overall direction. It validated the themes emanating from the interviews and provided a focus for discussion at the Western NSW Primary Health Workforce Forum.

\section{Step 8: conduct stakeholder interviews and analyse (approximately four months)}

Review of the academic literature informed development of the interview questions. Ethics approval for the interviews was obtained from Deakin University, Melbourne. In total, 41 
interviews were conducted with key stakeholders from a range of health workforce sectors. During the interviews, participants were asked their opinions, interests, ideas, concerns and priorities in relation to regional workforce planning issues and how these might be addressed. They reported similar challenges to those found in the partnership literature and these aligned with the domains of the Framework. In the area of workforce recruitment, the issues focused on how to gain access to suitably qualified and experienced staff and identifying new models for addressing need. In relation to workforce retention, concerns centred around improving working conditions, including clinical governance and leadership and securing opportunities for professional learning. Community factors such as feeling welcomed, engaging in social activities and having career and education opportunities for family members were also reported as areas impacting on workforce retention.

Interviews also sought an understanding of stakeholders' hopes for, and concerns about, working in partnership and to define success for the partnership. Participants were also asked to provide feedback on the Framework, which was overwhelmingly positive. Suggestions were later incorporated.

\section{Step 9: conducting the initial Western NSW primary health workforce forum (the forum)} (approximately three months)

In total, 32 organisations (68 people) accepted the invitation to participate in the Forum. The purpose of the Forum was to endorse the final Western NSW Primary Health Workforce Planning Framework, canvas further actions and agree on a way forward. A summary of the academic literature, key themes from the stakeholder interviews and a case study exemplar of collaborative practice in the region were presented to facilitate discussion and assist with completion of the 2030 Western NSW Primary Health Workforce Action Plan. Aligned to the six priority action areas outlined in the Framework, stakeholders were asked to consider how their organisations might map, align and commit to actions to operationalise the Framework. A second Forum was held to provide an update on the priority actions and confirm stakeholders' commitment to the partnership work. A communication strategy ensured the priority actions continued to be informed by the wider stakeholder group.

\section{Step 10: final project report and commitment to action (approximately two months)}

All stages of the project built the foundations for the development of 2030 Western NSW Primary Health Workforce Priority Action Plan (priority actions). In particular, the six action areas of the Framework provided a road map for developing the priority actions. The priority actions were considered against current NSW and national strategies and the strategies and local priorities of the partner organisations. The priority actions further engaged stakeholders and built their trust and confidence in the partnerships' ability to address complex rural primary health workforce issues in Western NSW. The commitment of the five organisations to resource the partnership for a further 18-month period, including the appointment of a Partnership Manager, was a significant outcome, reflecting both the positive beginnings and optimism about the future of this partnership approach.

\section{Step 11: monitoring and review, including governance meetings (ongoing)}

Monitoring and evaluation are key components for a successful partnership. While the project plan identified the key objectives and the work to be done from the outset, a comprehensive monitoring and evaluation process is being developed in order to gauge the partnership's true impact. Governance mechanisms will continue to be an important tool for 
JICA

28,2

154

providing direction, monitoring performance and managing both real and perceived conflicts of interest (Hardy et al., 2000), and these will be reviewed to ensure they continue to serve the needs of the partnership.

\section{Discussion}

There is great potential in partnerships that enable different people and organisations to support each other by leveraging, combining and capitalising on their complementary strengths and capabilities (Lasker et al., 2001). This paper described an evidence-informed model of partnership to engage stakeholders in a collaborative approach to addressing health workforce challenges in Western NSW. There is considerable literature that examines managerial perspectives, organisational and contextual factors and forms of partnership working that appear to be associated with effective partnerships (Glasby et al., 2006). There is also a growing body of literature that defines and analyses key issues affecting access to the improvement of health services in rural underserviced areas (Strasser et al., 2016). However, there are few case studies that examine partnership building within a rural context and absent from these discussions are the specific steps for building an integrated approach to health workforce in the rural context.

By outlining the carefully planned and multifaceted steps undertaken to implement a partnering approach in Western NSW, with consideration of existing evidence about the key elements of effective partnerships, this paper contributes to an understanding of collaborative work. Specifically, this paper contributes to knowledge about the partnership process, but may also provide useful direction for others embarking on multisectoral partnerships to address health challenges. The findings may also have implications with respect to fostering more realistic expectations about the magnitude of what is required to implement a successful partnership.

Numerous elements determine the success of efforts to develop effective partnerships in health and this contributes to the complexity of this process (Dowling et al., 2004; Lester et al., 2008; Wildridge et al., 2004; Woulfe et al., 2010). The literature as to what constitutes an effective partnership informed the development of the partnership principles and guided the development of the Western NSW Primary Health Workforce Partnership Model. The Model appears to be consistent with the literature about the key elements required to form a successful partnership. Our experience to date indicates that all steps in the process were important in identifying the mutual benefits that could be achieved through collaborative work and in gaining commitment from stakeholders to work together to develop and implement a Priority Action Plan over the next 10 years. The deep consultation laid the foundation for engagement and future collaborative work together.

\section{Leadership and investment by key partners}

Central to the success of the Western NSW partnership was the fact that leaders from the five key organisations mobilised collaboration by advocating for joining resources and capabilities to better address rural health workforce issues. Their commitment to a collective responsibility for the direction and activities of the collaboration generated stakeholder engagement. Not all leaders appreciate partners' different perspectives, can bridge their diverse cultures and are comfortable sharing ideas, resources and power (Lasker et al., 2001), but as Stewart (2002) observed, leadership can inspire shared vision, enthusiasm, commitment and trust among partners.

\section{Engagement to gain investment and commitment phase by other stakeholders}

The Model facilitated genuine participation and highlights the value of a clear process for engaging and committing stakeholders to joint action. The Western NSW Primary Health 
Workforce Planning Framework proved to be a robust and integral tool in engaging stakeholders in the development of a Priority Action Plan. One of the factors that appeared to be critical to the success of the broader engagement process was the ability to articulate what the partners could accomplish working together, and how their joint work would benefit not only Western NSW communities but also each of their organisations individually. This finding supports previous work on successful partnerships in health that recognise the importance of reaching agreement about the purpose for the partnership and developing a shared vision (Dowling et al., 2004; Peck et al., 2002; Wildridge et al., 2004).

Another key aspect of gaining investment by partners was the ability to articulate and gain agreement on a clear plan of action. As Hardy et al. (2000) observed, partnerships must find effective means of making decisions to ensure progress is maintained as they develop. Williamson (2001) also found that joint ownership of decisions and collective responsibility for the direction and activities of the collaboration are required.

Dhillon (2005) and Woulfe et al. (2010) found the basis of continued and effective partnerships depends on the social relationships amongst the people in the partnerships. In the Western NSW experience, the multiphased engagement process sought to develop a deep understanding of partners' perspectives and leaders of the partnership demonstrated strong relationship skills to foster respect, trust, inclusiveness and openness among partners. This multiphased engagement process fostered commitment and enabled partners to make investments specific to the Priority Action Plan, which was an outcome in itself. Dhillon (2005) also noted that this reliance on developing relationships amongst organisations and individuals makes the process of developing partnerships complex.

Building a trusting environment was central to the partnership process and helped to foster a shared vision and purpose. Building trust was also important in managing the inherent tensions in gaining co-operation where there had been a history of competition. In breaking down competition and gaining a commitment of effort and resource, it was important to include the public, private, not for profit and community-controlled sectors in the engagement process. According to Wildridge et al. (2004), it is possible to work jointly with little trust between partners; however, the most successful partnerships have and work hard to maintain a strong level of mutual trust. Dhillon (2005) also noted that trust and shared values hold the partnership together. Engagement and trust have been further strengthened by the Western NSW Primary Health Workforce Partnership Model becoming the umbrella for all rural workforce efforts undertaken in the region.

\section{Building and maintenance phase}

Integral to the maintenance phase was ensuring processes such as communication, governance and decision-making and reporting were in place. Mohr et al. (2004) proposed that the administration and management of a partnership is the "glue" that makes it possible for multiple, independent people and organisations to work together. Maintaining attention on these factors positively affected the creation of an environment to maintain good working relationships, to steer, guide and account for the activities and programs implemented. Facilitating good and efficient communication among partners was important to enable transparency in decision making, more effective participation, planning for future activities and growth of the partnership (Woulfe et al., 2010).

Effective governance and management were consistently identified both in the partnership literature and in stakeholder feedback as priorities for successful implementation of a partnership approach and so these aspects formed an early part of the work. The recent appointment of a Partnership Manager and the establishment of a Steering Committee provided the mechanisms to help progress the priority actions outlined in the Framework. The Partnership Manager is the bridge between the organisations and the project champions.
Rural health workforce challenges 
JICA

28,2

156

The leadership provided by the members of an advisory group representing a range of health workforce sectors will help drive achievement of the actions.

In addition to the enablers, partnerships experience constraints or limiting factors. In Western NSW, there is goodwill among organisations, but little funding support beyond this initial establishment phase to implement the priority actions. Funding is important not only for implementing priority actions, but also for establishing and maintaining proper evaluation for activities. Although resources alone do not ensure the success of partnerships, how partnerships are funded and supported does influence their functioning (Cameron and Lart, 2003; Wolff, 2001). Given the long-term nature of the Priority Action Plan and the approach, sustained commitment is crucial. It will be important to identify those factors that enable sustained commitment to working together. Fund pooling has enabled the establishment of the partnership approach and engaged the Partnership Manager, but a long-term approach requires further financial commitment.

\section{Conclusion}

Our experience to date demonstrates the potential of an evidence-informed approach to partnership engagement to better address the challenges of recruiting and retaining a rural health workforce in Western NSW. We outlined the practical steps undertaken to implement a partnership approach aimed at improving the rural primary health workforce in Western NSW. The partnership involved a number of key stakeholders from a range of health workforce sectors in NSW to implement a range of mutually agreed actions. The process facilitated engagement of key stakeholders supported by agreed principles for the collaboration. Engaging stakeholders in a variety of ways, including discussions with CEOs and clinical leads, attending meetings with stakeholder groups, conducting interviews and hosting an initial Forum, were critical to understanding the best ways to address the issues and for gaining endorsement and clarity about how to work together to achieve positive change. The development of the Western NSW Primary Health Workforce Planning Framework and the Priority Action Plan provided the blueprint for the way forward.

Drawing on the extensive literature about partnership working, this paper contributes to existing knowledge by enhancing understanding of rural partnerships. The paper and the Western NSW Primary Health Workforce Partnership Model presented provide important information for developing partnership approaches to enhance primary health care delivery in rural and remote regions, and gives cause for optimism. The paper not only adds to our understanding of the partnership process, but it may also provide useful direction for leaders of other large partnerships and facilitate the development of similar models across other parts of NSW, wider Australia and internationally. What is clear is the issue of partnership and its effective enablers must be given careful consideration, and structures employed to ensure long-term commitment.

While the process is yet to be evaluated in terms of its outputs, the partnership process indicators suggest the partnership is healthy, in terms of harmonious relationships, agreement on key action areas and engagement in the process of implementing the actions. It is crucial to retain continuous and effective communication between all stakeholders to ensure that we can meet the many challenges of addressing rural primary health care workforce issues. Success in the longer-term, in other words how well the partnership achieves its current aims, and the long-term sustainability of the partnership, is still to be determined. With a heightened emphasis on translation work to improve practice, there is an opportunity for health and social care organisations to become effective places to trial and evaluate partnership efforts, with a view to sharing good practice. Other regions in NSW have expressed interest in adopting the approach. The tools are broadly applicable and the priority actions could be tailored to meet the specific service needs of any region. 


\section{Note}

1. The Modified Monash Model is a new classification system used in Australia that better categorises metropolitan, regional, rural and remote areas according to both geographical remoteness and town size (DoH, 2018).
Rural health workforce challenges

\section{References}

ABS (2018), "Regional population growth, Australia 2007-2017”, Cat. No. 3218.0, Australian Bureau of Statistics, Belconnen, available at: http://stat.abs.gov.au/itt/r.jsp?databyregion\#/ (accessed 2 April 2019).

AIHW (2014), “Australia's health 2014”, Australia's Health Series No. 14, Cat. No. AUS 178, Australian Institute of Health and Welfare, Canberra, pp. 1-56.

AIHW (2016), “About primary health care”, Australian Government, Australian Institute of Health and Welfare, Canberra, pp. 1-3, available at: www.aihw.gov.au/reports-data/health-welfare-services/ primary-health-care/overview (accessed 13 March 2019).

AIHW (2018), “Australia's health 2018”, Cat. no: AUS 222, Australian Government, Australian Institute of Health and Welfare, Canberra, pp. 1-56, available at: www.aihw.gov.au/getmedia/fe037cf1-0 cd0-4663-a8c0-67cd09b1f30c/aihw-aus-222.pdf.aspx?inline=true (accessed 13 March 2019).

Australian Government (2016), "National strategic framework for rural and remote health", available at: www.health.gov.au/internet/main/publishing.nsf/Content/national-strategic-frameworkrural-remote-health (accessed 2 April 2019).

Australian Government Primary Health Network Western NSW (2019), "Health profile 2019 Western NSW Primary Health Network", available at: www.wnswphn.org.au/about-us/who-we-are (accessed 2 April 2019).

Borrill, C. and West, M. (2002), Team Working and Effectiveness in Health Care: Fndings from the Health Care Team Effectiveness Project, Aston Centre for Health Service Organisation Research, Birmingham, pp. 1-11.

Brinkerhoff, J. (2002), "Government-nonprofit partnership: a defining framework", Public Administration and Development, Vol. 22 No. 1, pp. 19-30.

Cameron, A. and Lart, R. (2003), "Factors promoting and obstacles hindering joint working: a systematic review of the research evidence”, Journal of Integrated Care, Vol. 11 No. 2, pp. 9-17.

D’Amour, D., Goulet, L., Labadie, J.F., San Martin-Rodriguez, L. and Pineault, R. (2008), “A model and typology of collaboration between professionals in healthcare organizations", BMC Health Services Research, Vol. 8 No. 188, pp. 1-14.

Dhillon, J.K. (2005), "The rhetoric and reality of partnership working", Journal of Further and Higher Education, Vol. 29 No. 3, pp. 211-219.

Dixit, S. and Sambasivan, M. (2018), "A review of the Australian healthcare system: a policy perspective”, Sage Open Medicine, Vol. 6, pp. 1-14, doi: 10.1177/2050312118769211.

DoH (2015), "Primary health networks (PHNs)", Australian Government Department of Health, Canberra, available at: www.health.gov.au/internet/main/publishing.nsf/Content/primary_ Health_Networks (accessed 24 April 2019).

DoH (2018), "The modified Monash Model”, Australian Government Department of Health, Australia Government, Canberra, available at: www.health.gov.au/internet/main/publishing.nsf/Content/ modified-monash-model (accessed 18 February 2019).

Dowling, B., Powell, M. and Glendinning, C. (2004), "Conceptualising successful partnerships”, Health \& Social Care in the Community, Vol. 12 No. 4, pp. 309-317.

Farmer, J. and Kilpatrick, S. (2009), "Are rural health professionals also social entrepreneurs?”, Social Science \& Medicine, Vol. 69 No. 11, pp. 1651-1658.

Glasby, J., Dickinson, H. and Peck, E. (2006), "Guest editorial: partnership working in health and social care", Health and Social Care in the Community, Vol. 14 No. 5, pp. 373-374. 
JICA

28,2

158

Glasby, J., Miller, R. and Dickinson, H. (2011), "Partnership working in England - where we are now and where we've come from", International Journal of Integrated Care, Vol. 11 No. 7, pp. 1-8.

Glendinning, C. (2002), "Partnerships between health and social services: developing a framework for evaluation", Policy \& Politics, Vol. 30 No. 1, pp. 115-127.

Hardy, B., Hudson, B. and Waddington, E. (2000), What Makes a Good Partnership?, Nuffield Institute for Health, Leeds.

Hayes, S., Mann, M., Morgan, F., Kelly, M. and Weightman, A. (2012), "Collaboration between local health and local government agencies for health improvement", Cochrane Database of Systematic Reviews, Vol. 10, pp. 1-139.

Henneman, E.A., Lee, J.L. and Cohen, J.I. (1995), "Collaboration: a concept analysis", Journal of Advanced Nursing, Vol. 21 No. 1, pp. 103-109.

Herranz, J. (2010), "The logic model as a tool for developing a network performance measurement system”, Public Performance \& Management Review, Vol. 34 No. 1, pp. 56-80.

HIU (2017), "Health of the population: western NSW stage I health needs assessment", unpublished manuscript, Western NSW Local Health District, Health Intelligence Unit, Dubbo, NSW, December.

Holtom, M. (2001), "The partnership imperative. Joint working between social services and health", Journal of Management in Medicine, Vol. 15 No. 6, pp. 430-445.

Humphreys, J., Wakerman, J., Wells, R., Kuipers, P., Jones, J. and Entwistle, P. (2008), “'Beyond workforce': a systemic solution for health service provision in small rural and remote communities”, Medical Journal of Australia, Vol. 188 No. 8, p. S77.

Keleher, H. (2015), "Partnerships and collaborative advantage in primary care reform”, Deeble Institute Evidence Brief No. 13, Canberra.

Kendall, E., Muenchberger, H., Sunderland, N., Harris, M. and Cowan, D. (2012), "Collaborative capacity building in complex community-based health partnerships: a model for translating knowledge into action", Journal of Public Health Management Practice, Vol. 18 No. 5, pp. E1-E13.

Lasker, R.D., Weiss, E.S. and Miller, R. (2001), "Partnership synergy: a practical framework for studying and strengthening the collaborative advantage", Milbank Quarterly, Vol. 79 No. 2, pp. 179-205.

Lester, H., Birchwood, M., Tait, L., Shah, S., England, E. and Smith, J. (2008), "Barriers and facilitators to partnership working between early intervention services and the voluntary and community sector", Health \& Social Care in the Community, Vol. 16 No. 5, pp. 493-500.

Markwell, S. (2003), Partnership Working: A Consumer Guide to Resources, HDA, London.

Mitchell, S.M. and Shortell, S.M. (2000), "The governance and management of effective community health partnerships: a typology for research, policy, and practice”, The Milbank Quarterly, Vol. 78 No. 2, pp. 241-289, 151.

Mohr, J., Batalden, P. and Barach, P. (2004), "Integrating patient safety into the clinical microsystem", Quality and Safety in Health Care, Vol. 13 No. SII, pp. ii34-ii38.

NSW Government (2017), "Health Stats NSW, population by Primary Health Networks", available at: www.healthstats.nsw.gov.au/Indicator/dem_pop_phnmap/dem_pop_phn_age_trend (accessed 22 April 2019).

OECD LEED (2006), Forum on Partnerships and Local Governance, Organisation for Economic Co-operation and Development, pp. 1-35, available at: www.oecd.org/cfe/leed/forum/ partnerships (accessed 30 November 2018).

OECD (2017), "Health at a Glance 2017", OECD Indicators, Organisation for Economic Co-operation and Development, Paris.

Peck, E., Gulliver, P. and Towell, D. (2002), Modernising Partnerships. An Evaluation of Somerset's Innovations in the Commissioning and Organisation of Mental Health Services, Institute for Applied Health Social Policy, London. 
Pearson, C. and Watson, N. (2018), "Implementing health and social care integration in Scotland: renegotiating new partnerships in changing cultures of care", Health and Social Care in the Community, Vol. 26 No. 3, pp. e396-e403.

Petch, A., Cook, A. and Miller, E. (2013), "Partnership working and outcomes: do health and social care partnerships deliver for users and carers?", Health and Social Care in the Community, Vol. 21 No. 6, pp. 623-633.

PHIDU (2019), "Social Health Atlases of Australia Torrens University of Australia", Public Health Information Development Unit, Adelaide, available at: www.phidu.torrens.edu.au/social-healthatlases/data (accessed 5 May 2019).

Powell, M. and Exworthy, M. (2002), "Partnerships, quasi-networks and social policy", in Glendinning, C., Powell, M. and Rummery, K. (Eds), Partnerships, New Labour and the Governance of Welfare, Policy Press, Bristol, pp. 15-32.

Stewart, M. (2002), Systems Governance: Towards Effective Partnership Working, Health Development Agency Seminar Series on Tackling Health Inequalities, University of the West of England, Bristol and London.

Strasser, R., Kam, S. and Regalado, S. (2016), "Rural health care access and policy in developing countries", Annual Review of Public Health, Vol. 37 No. 1, pp. 395-412.

Taylor-Robinson, D.C., Lloyd-Williams, F., Orton, L., Moonan, M., O'Flaherty, M. and Capewell, S. (2012), "Barriers to partnership working in public health: a qualitative study", PLoS One, Vol. 7 No. 1, p. e29536, doi: 10.1371/journal.pone.0029536.

Wakerman, J. and Humphreys, J. (2011), "Sustainable primary health care services in rural and remote areas: innovation and evidence", Australian Journal of Rural health, Vol. 19 No. 3, pp. 118-121.

WHO (1986), The Ottawa Charter for Health Promotion, World Health Organization, Geneva, available at: www.who.int/healthpromotion/conferences/previous/ottawa/en/index.html (accessed 16 April 2019).

Wildridge, V., Childs, S., Cawthra, L. and Madge, B. (2004), "How to create successful partnerships - a review of the literature", Health Information and Libraries Journal, Vol. 21 No. S1, pp. 3-19.

Williamson, V. (2001), "The potential of project status to support partnerships", in Balloch, S. and Taylor, M. (Eds), Partnership Working Policy and Practice, Policy Press, Bristol, pp. 117-141.

Willis, C., Greene, J., Abramowicz, A. and Riley, B. (2016), "Health promotion and chronic disease prevention in Canada", Research, Policy and Practice, Vol. 36 No. 6, pp. 101-111.

Wolff, T. (2001), “A practitioner's guide to successful coalitions”, American Journal of Community Psychology, Vol. 29 No. 2, pp. 173-191.

Woulfe, J., Oliver, T.R., Zahner, S.J. and Siemering, K.Q. (2010), "Multisector partnerships in population health improvement", Preventing Chronic Disease, Vol. 7 No. 6, available at: www.cdc.gov/pcd/ issues/nov/10_0104.htm (accessed 2 April 2019).

\section{Further reading}

Borrill, C., West, M., Shapiromm, D. and Rees, A. (2000), "Team working and effectiveness in health care”, British Journal of Healthcare Management, Vol. 6 No. 8, pp. 364-371.

OECD (2015), OECD Reviews of Health Care Quality: Australia 2015: Raising Standards, OECD Reviews of Health Care Quality, Organisation for Economic Co-operation and Development Publishing, Paris, available at: https://doi.org/10.1787/9789264233836-en 
Figure A1.

The Western NSW

Primary Health

Workforce Planning

Framework
Vision

Western NSW will have an integrated, long term approach to workforce planning to increase access to high quality primary health care in a timely and affordable manner-no matter where people live

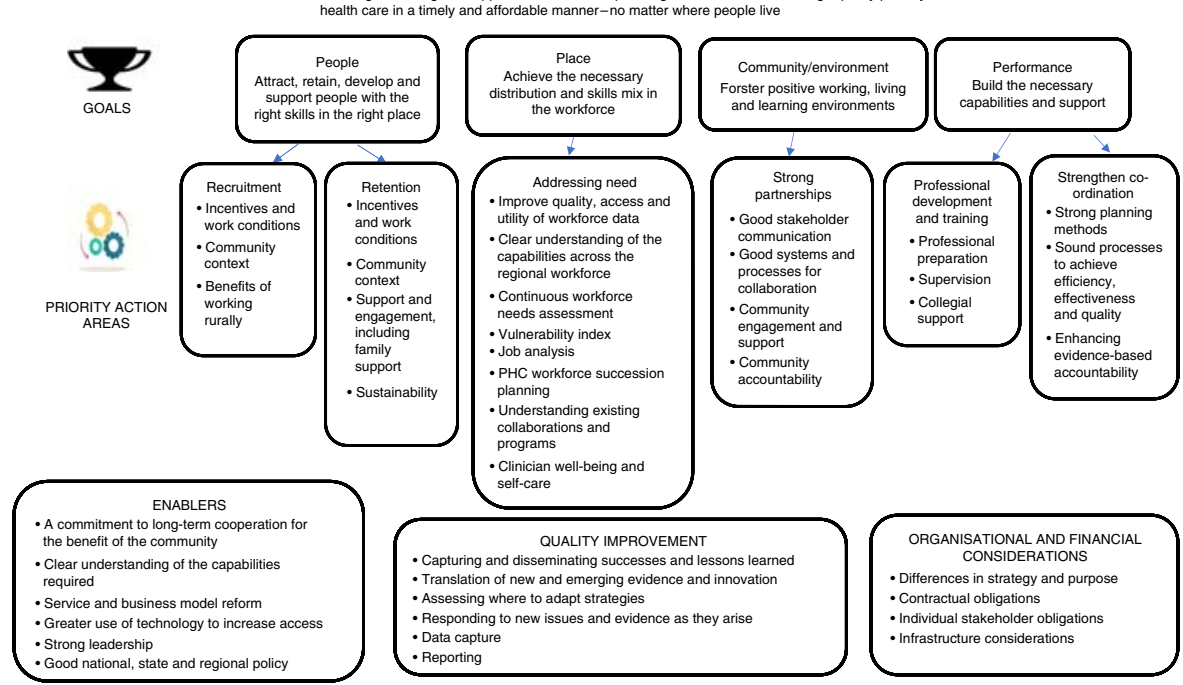

Corresponding author

Robyn Ramsden can be contacted at: rgwaghorne@gmail.com

For instructions on how to order reprints of this article, please visit our website:

www.emeraldgrouppublishing.com/licensing/reprints.htm

Or contact us for further details: permissions@emeraldinsight.com 